\title{
EVALUATION OF SHOCK MITIGATING MATERIALS IN A V-BAND PYROSHOCK ENVIRONMENT SIMULATED WITH A RESONANT FIXTURE*
}

\author{
Vesta I. Bateman and Fred A. Brown \\ Sandia National Laboratories \\ Albuquerque, NM 87185
}

\section{Authors' Biographies}

Vesta I. Bateman received a B.S. degree from Vanderbilt University and a M.S. and Ph.D. from the University of Arizona, all in Mechanical Engineering. She taught for four years in the Mechanical Engineering Department at Virginia Tech. Since 1980, she has been at Sandia National Laboratories in Albuquerque, New Mexico where she is a Senior Member of the Technical Staff in the Mechanical Shock Testing Laboratory.

Fred A. Brown has over twenty years of shock testing experience in the Mechanical Shock Laboratory at Sandia National Laboratories $\mathrm{He}$ has participated in the development of many different types of shock-producing mechanisms including resonant fixturing for pyroshock simulation, Hopkinson bar testing for component evaluation, and innovative drop table configurations for specialized shock requirements.

\section{Abstract}

An explosively activated V-band joint is used on a multistage rocket payload to release components at prescribed times in the rocket's flight and creates a pyroshock environment that the other payload components must survive. Accelerometer response data was measured close to an actual V-band pyroshock. With the shock spectra calculated from these data, a resonant fixture was designed to simulate a V-band pyroshock event. The characteristics of the data and the design process are described. Laboratory tests were conducted to determine that the desired shock spectra with an unusually high knee at about $8,000 \mathrm{~Hz}$. was produced with the resonant fixture. The fixture was then mounted on a 29 in. diameter, 2 in. thick plate simulation of a payload plate. Simulated electronic components were also mounted on the plate. The pyroshock environment simulation was created by the resonant fixture response to a projectile impact, and the component response to the environment was measured at the electronic components.

\footnotetext{
This work was supported by the U.S. Department of Energy under DE-AC04-94AL85000.

The component responses to the pyroshock were measured with five different shock mitigating materials inserted between the resonant fixture and the payload plate simulation, and the peak response values were tabulated.

\section{Keywords \\ Background}

Pyroshock, resonant fixture, pyrotechnic shock simulation

The T01 payload was designed to include a V-band joint for release of components at prescribed times during a multistage rocket flight. An experiment was performed to characterize the shock environment experienced by the T01 payload with the V-band release of the payload from the ejector and to measure the spin rate and the ejection velocity. The test configuration is shown schematically in Figure 1. In this experiment, the T01 payload was represented by a cylindrical mass attached to a conical

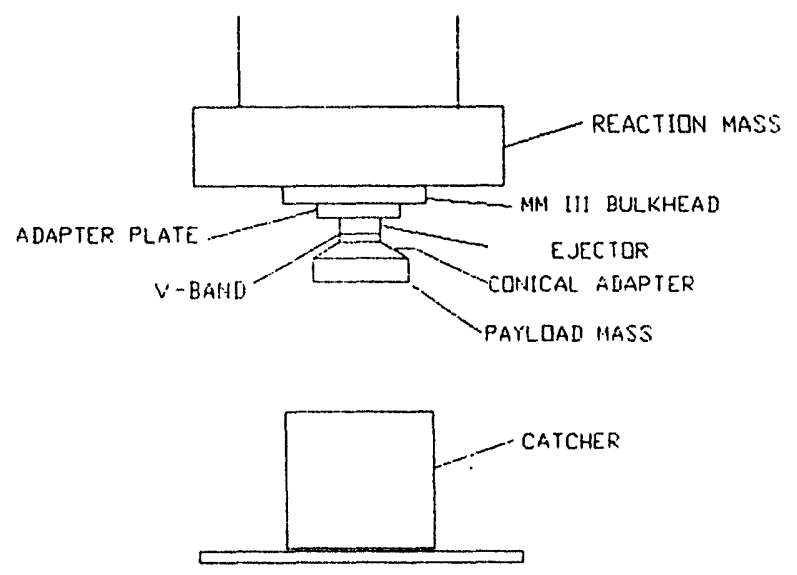

Figure 1: T01 Ejection Test Configuration

adapter which has the correct interface with the ejector. These two items had a total weight of $97 \mathrm{lbs}$ and the same roll moment of inertia as the actual payload. The payload was held to the ejector by a V-band secured with a bolt cutter which was electrically initiated An example of a V-band is shown in Figure 2. High frequency, high glevel accelerometers were mounted in triaxial assemblies 


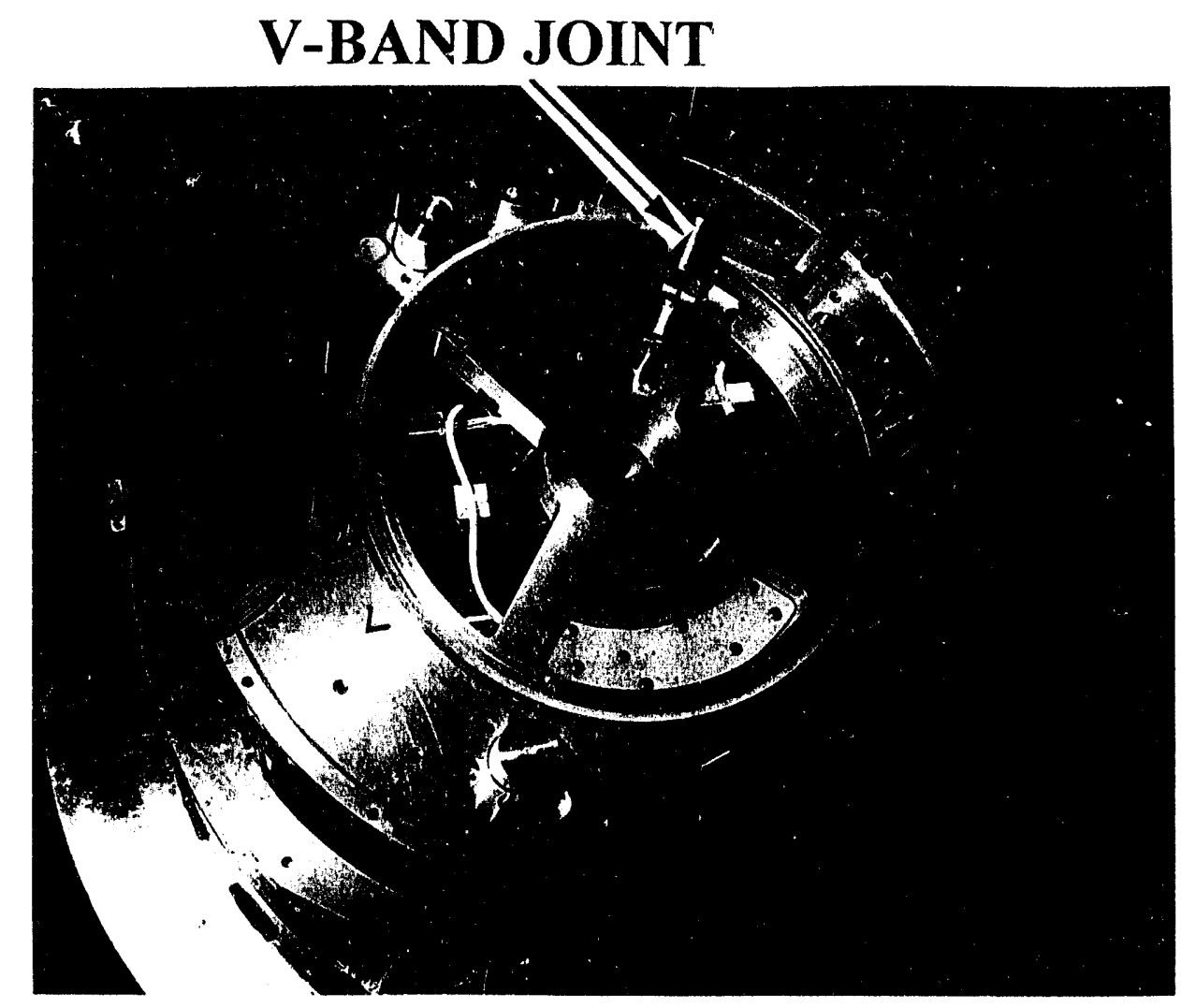

Figure 2: Example of V-Band Joint (Top View).

in cavities in the conical adapter and on the cylindrical steel mass. Hardmounted accelerometers in the cavity locations had failed in previous tests. That is, the accelerometers had zero-shifted during the test and rendered the data useless. Endevco 7270A-20k accelerometers mounted in the disk isolation technique developed at Sandia National Laboratories were used for this test [1,2]. High speed cameras were used to determine roll rate and separation velocity. All data for this test were successfully measured. The roll rate was determined to be within $5 \%$ of the nominal $1.0 \mathrm{rps}$, and the velocity was within $5 \%$ of the nominal 2 fps. A typical acceleration time history is shown in Figure 3 and its corresponding shock spectrum is shown in Figure 4 [3]. The time history shows the high frequency, decayed sinusoid character of the structural response to a pyrotechnic event. The envelope is symmetrical and decays back to a zero baseline in about $20 \mathrm{~ms}$. The shock spectrum in Figure 4 shows the high slope typical of pyroshock $(+2$ on a $\log -\log$ plot) between $500 \mathrm{~Hz}$ and about $8000 \mathrm{~Hz}$. The shock spectrum knee is at about $8000 \mathrm{~Hz}$ which is an unusually high frequency. Above $8000 \mathrm{~Hz}$, the shock spectrum levels off. This shock

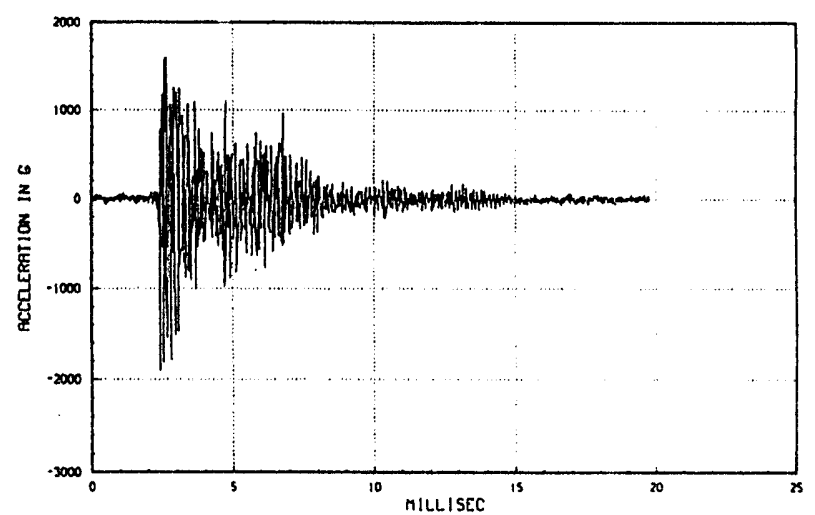

Figure 3: Typical Acceleration Time History for the T01 Ejector Test 


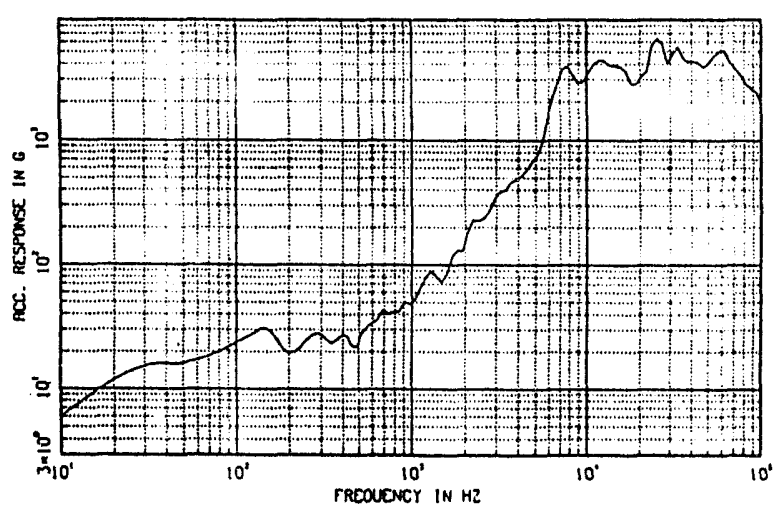

Figure 4: Shock Spectrum Corresponding to Figure 3.

spectrum was used to represent the T01 Ejector pyroshock environment created by the V-band release. Components mounted in an electronics rack as part of the payload had to operate during and after exposure to this environment.

\section{Resonant Fixture Design}

Since the components on the T01 payload for the multistage rocket using the ejector had to be tested prior to the payload launch, a resonant fixture was designed to simulate the environment in Figure 3. The general design procedure is to chose the fixture dimensions so that its predominant vibrational frequency is the same as the knee frequency in the shock spectrum. Usually, a resonant fixture is designed to meet the shock spectrum requirements, and the components are bolted directly to the fixture which is impacted with a projectile accelerated by an air gun. The resonant fixture is large in comparison to the smaller component attached to the fixture so that the fixture response drives the shock environment created by a projectile impact on the fixture.

In this case, it was desired to simulate the actual path between the pyroshock and the components, so a different configuration was proposed for the simulation: a relatively small resonant fixture was designed to bolt directly to a larger structure, a simulated payload plate. In this configuration, the resonant fixture does not drive the entire structure, but provides a simulation of the pyroshock source at a particular location on the large structure. This approach allowed the testing of many components with one test configuration. If the usual pyroshock configuration was used, it would be necessary to design and construct many different resonant fixtures (probably one for each component). The dimensions of the resonant fixture were chosen to be close to the actual structure supporting the payload with the $\mathrm{V}$-band joint and to create a resonant response at a frequency close to the predominant frequency in the shock spectrum.

The first resonance of the resonant fixture was calculated using the equation below [4]:

$$
f_{n}=B \frac{t}{2 \pi a^{2}} \sqrt{\frac{E}{\rho\left(1-\mu^{2}\right)}}
$$

where: $f_{n}=$ resonant frequency $(\mathrm{Hz})$,

$B=$ mode shape factor from [4],

$\mathrm{t}=$ plate thickness (in),

$a=$ plate diameter (in),

$\mathrm{E}=$ modulus of elasticty (psi),

$\rho=$ density $\left(\mathrm{lb}-\sec ^{2} / \mathrm{in}^{4}\right)$, and

$\mu=$ Poisson's Ratio.

For a circular, aluminum plate with free-free boundary conditions, thickness of 4 in. and diameter of 10.1 in., $f_{1}$ and $f_{2}$ are $8 \mathrm{kHz}$ and $13.8 \mathrm{kHz}$, respectively. For the same circular plate with clamped boundary conditions, $f_{1}$ is $15.6 \mathrm{kHz}$. In many cases, it has been found that a simplified beam analysis adequately predicts the resonant frequency for a plate and may be calculated from the simplified equation for the first resonance of an aluminum beam with rectangular cross-section [5]:

$$
f_{1}=203,800 \frac{t}{a^{2}}
$$

This equation applies to beams for both free-free and fixed-fixed end conditions. Equation (2) predicts the first beam resonance to be $8 \mathrm{kHz}$. It was anticipated that the actual first resonance, a bending frequency, would be lower than $8 \mathrm{kHz}$ because of the support structure added to simulate the actual shock path. Since both the beam and the plate analyses predicted resonant frequencies of 8 $\mathrm{kHz}$ or higher, the thickness of the resonant fixture was chosen as 4 in.. This choice allows the removal of material to lower the frequency and was used because it would be impossible to add material to the fixture after it was built. There was some uncertainty in the resonant fixture design because it was not known that the above equations apply to plates and beams with thicknesses as large as 4 in. 
As shown in Figure 5, the resonant fixture is a 4 in. thick, circular plate with a 2 in. high, integral cylindrical support that bolts directly to the payload plate simulation. The fixture base has the same diameter, thickness, and bolt pattern as the actual structure. It is the four inch thick portion of the fixture that is predicted to resonate at the desired frequency of $8 \mathrm{kHz}$ or higher.

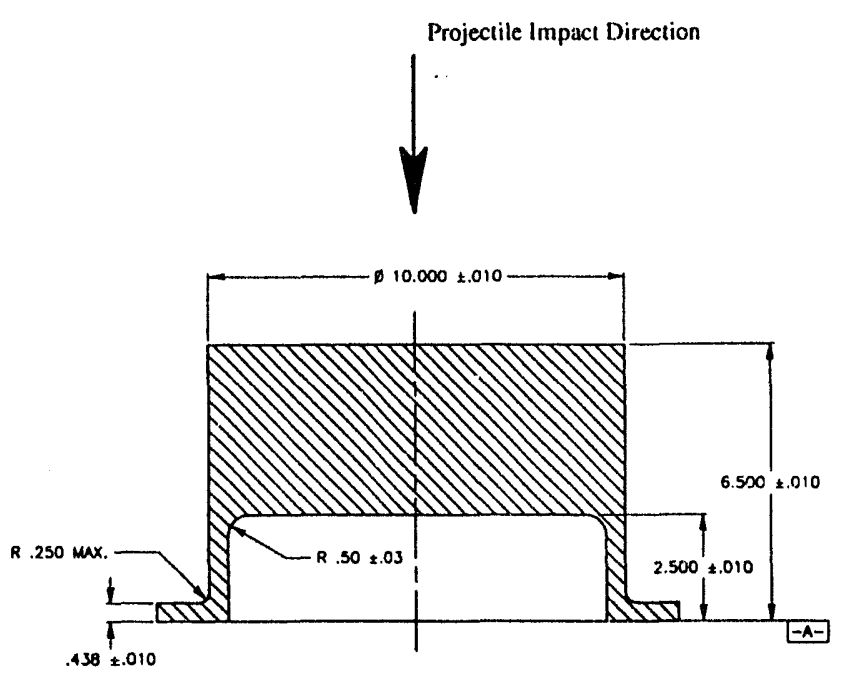

Figure 5: Schematic Drawing of the Resonant Fixiure used for V-Band Simulation

\section{Resonant Fixture Testing}

A straight line approximation was made to the shock spectrum in Figure 4, and the usual $\pm 6 \mathrm{~dB}$ tolerance for pyroshock was drawn on the plot as shown in Figure 6. This is the customary procedure for determing if a shock spectrum requirement is met. The straight line approximation and the corresponding $\pm 6 \mathrm{~dB}$ tolerance was used for all experiments to insure that the V-band simulation created the correct shock environment.

Initially, the resonant fixture was suspended by a rope at the end of the $3 / 4 \mathrm{in}$. air gun as shown in Figure 7. This configuration simulates a free-free boundary condition and allowed the measurement of the resonant fixture's response to projectile impact. Accelerometers were mounted on two sides of a small block and bonded to the side of the fixture as shown. Since the fixture is symmetrical, measurements were made in only one location. The shock spectrum for the resonant fixture's response to a typical impact is shown in Figure 8. In this

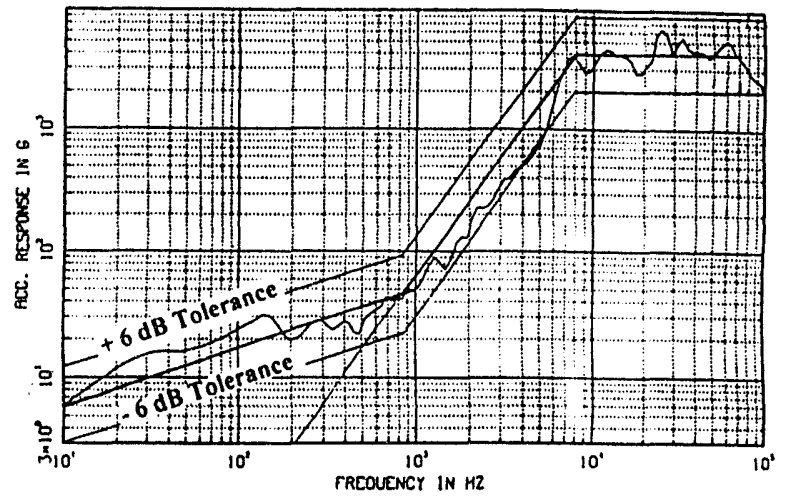

Figure 6: Shock Spectrum Straight Line Approximation and $\pm 6 \mathrm{~dB}$ Tolerance.

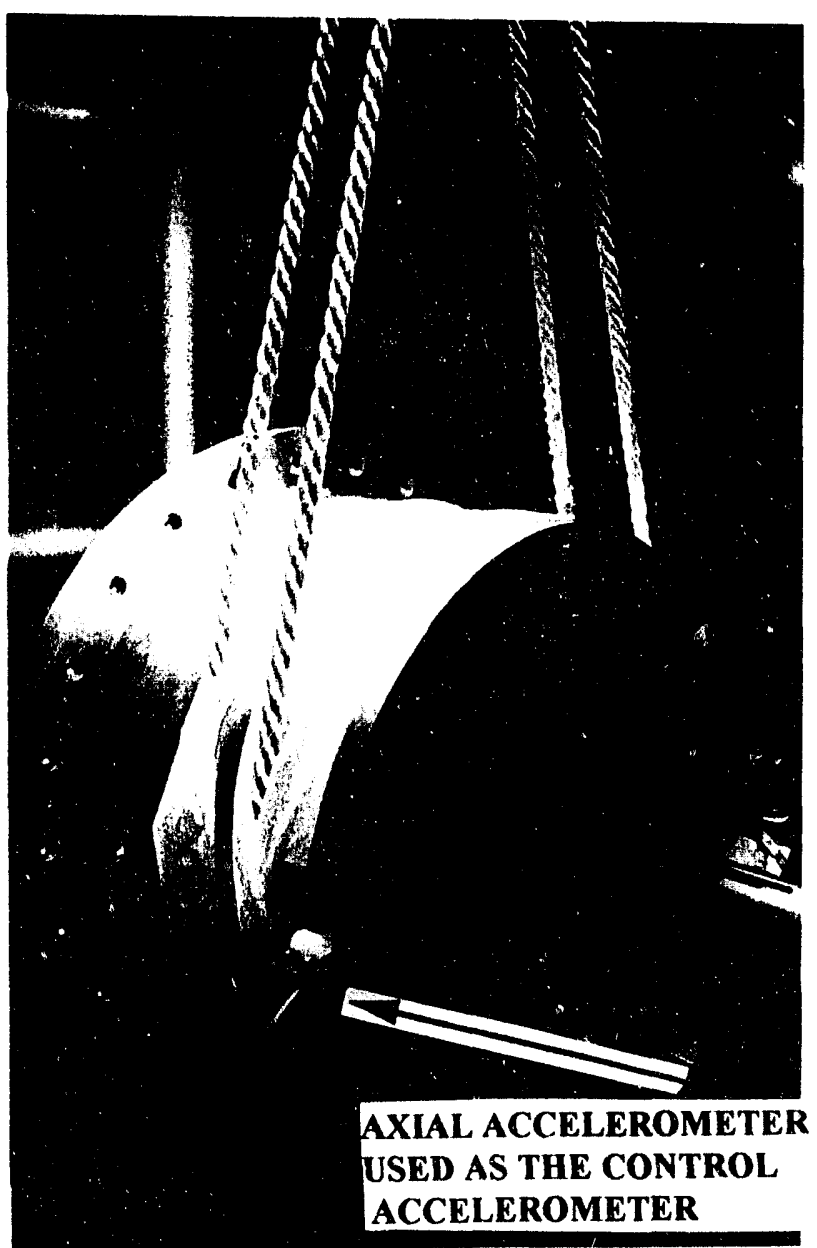

Figure 7: Resonant Fixture Test Configuration with Free Boundary Conditions. 


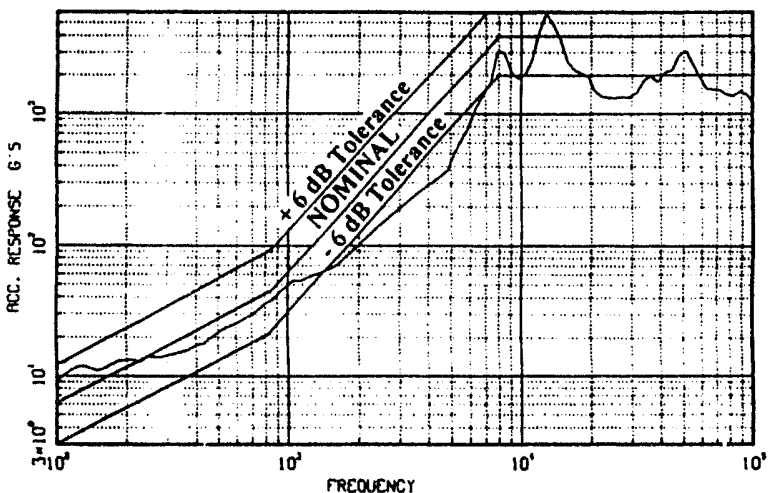

Figure 8: Shock Spectrum of Resonant Fixture Response with Free-Free Boundary Conditions.

configuration, the second resonance of the fixture at about $14 \mathrm{kHz}$ is more dominant than the first resonance at about $8 \mathrm{kHz}$ [4]. This measurement confirmed the analytical predictions and provided insight as to the fixture's resonant response without the rest of the simulation hardware.

The resonant fixture was next mounted on the simulated payload plate and impacted with a projectile. This configuration is shown in Figure 9. Acceleration measurements were made on either side of the resonant fixture. The accelerometers were mounted on small blocks and bonded to locations on the fixture $180^{\circ}$ apart on the fixture circumference. These accelerometers were used as the control accelerometers in the shock testing. One accelerometer location can be seen in the picture. Other accelerometers were mounted at the base of the fixture and can also be seen in the picture. The accelerometer's axis is oriented in the direction of the projectile impact. The shock spectra for two measurements on either side of the fixture are shown in Figure 10. The dominant frequency in the shock spectra has been lowered in this configuration to less than $10 \mathrm{kHz}$ which was the desired result.

Accelerometers were mounted in the electronics rack as shown in Figure 11. The electronics rack was mounted on the simulated payload plate. A typical time history of the resonant fixture acceleration response is shown in Figure 12. The fixture response has the usual characteristics of a pyroshock. The acceleration response

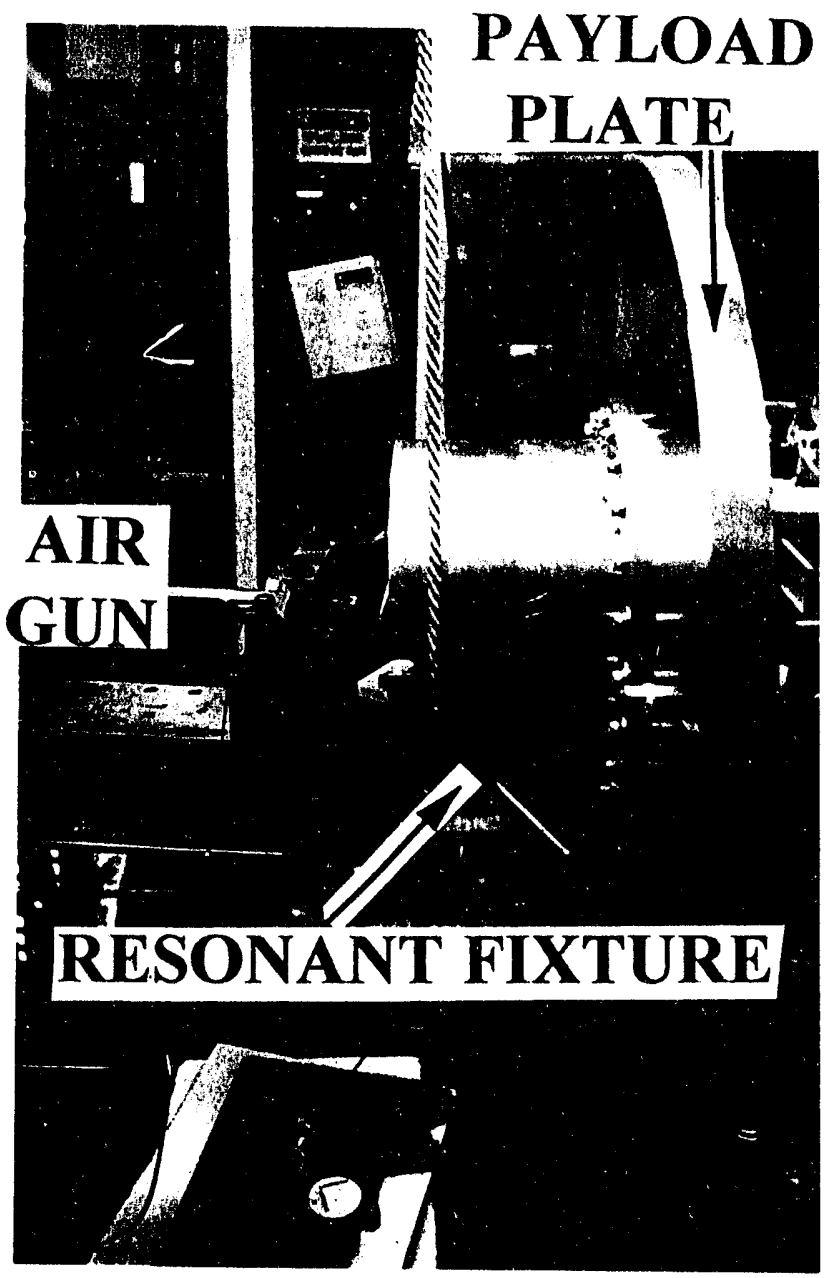

Figure 9: Test Configuration for Resonant Fixture Mounted on a Simulated Payload Plate.

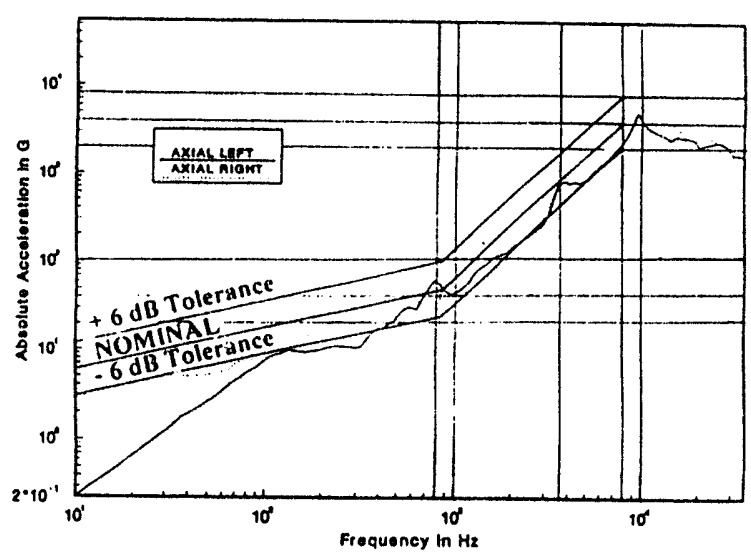

Figure 10: Shock Spectrum for the Resonant Fixture Mounted on a Simulated Payload Plate. 
is two-sided with no apparent velocity change and decays to zero within a reasonable time of about $20 \mathrm{~ms}$. The peak magnitude is approximately $\pm 2000 \mathrm{~g}$. The corresponding shock spectra are shown in Figure 13 which indicates that the dominant frequency has decreased again and that the resonant fixture is providing an excellent simulation of the $\mathrm{V}$-band pyroshock environment in this final test configuration shown in Figure 14. Typical shock spectra of the acceleration response in the electronics rack are shown in Figure 15.

\section{Shock Mitigating Material Testing and Selection}

The acceleration levels measured in the rack ranged from $\pm 250 \mathrm{~g}$ at Level 1 to $\pm 120 \mathrm{~g}$ at Level 5 and were too high for the components. Consequently, shock-mitigating material was placed in between the flange of the resonant fixture and the simulated payload plate. The assembly was bolted together, and the acceleration levels in response to an impact on the fixture were measured in the electronics rack. This procedure was repeated for five candidate shock mitigating materials: ren shape 450 , balsa wood, rigidamp (one layer), gore-tex, and rigidamp (two layers). Ren Shape 450 is a man-made material and is a registered trademark of the Ciba-Geigy Corporation. Balsa wood is the naturally occurring wood. Rigidamp introduces high damping into structures by laminating the structural materials with thin layers of viscoelastic damping material and is a registered trademark of Barry Controls. Gore-Tex is a 1/8 in. thick layer of Gore-Tex GR Sheet Gasketing and is a registered trademark of W. L. Gore \& Associates, Inc.

The peak acceleration values for the fixture and three measurement locations in the electronics rack are summarized in the table below. All the materials provided some shock mitigation. However, two layers of rigidamp provided no more isolation than one layer of rigidamp. This may indicate that the shock mitigation was achieved primarily by impedance mismatch. Details of the responses were examined in time history plots, Fourier transforms, and the shock spectra for the various measurement locations. A single layer of rigidamp was chosen as the shock mitigating material because it lowered the acceleration levels sufficiently in the electronics rack and it was easy to incorporate into the assembly. Two layers of rigidamp did not significantly lower the acceleration levels to warrant its use.

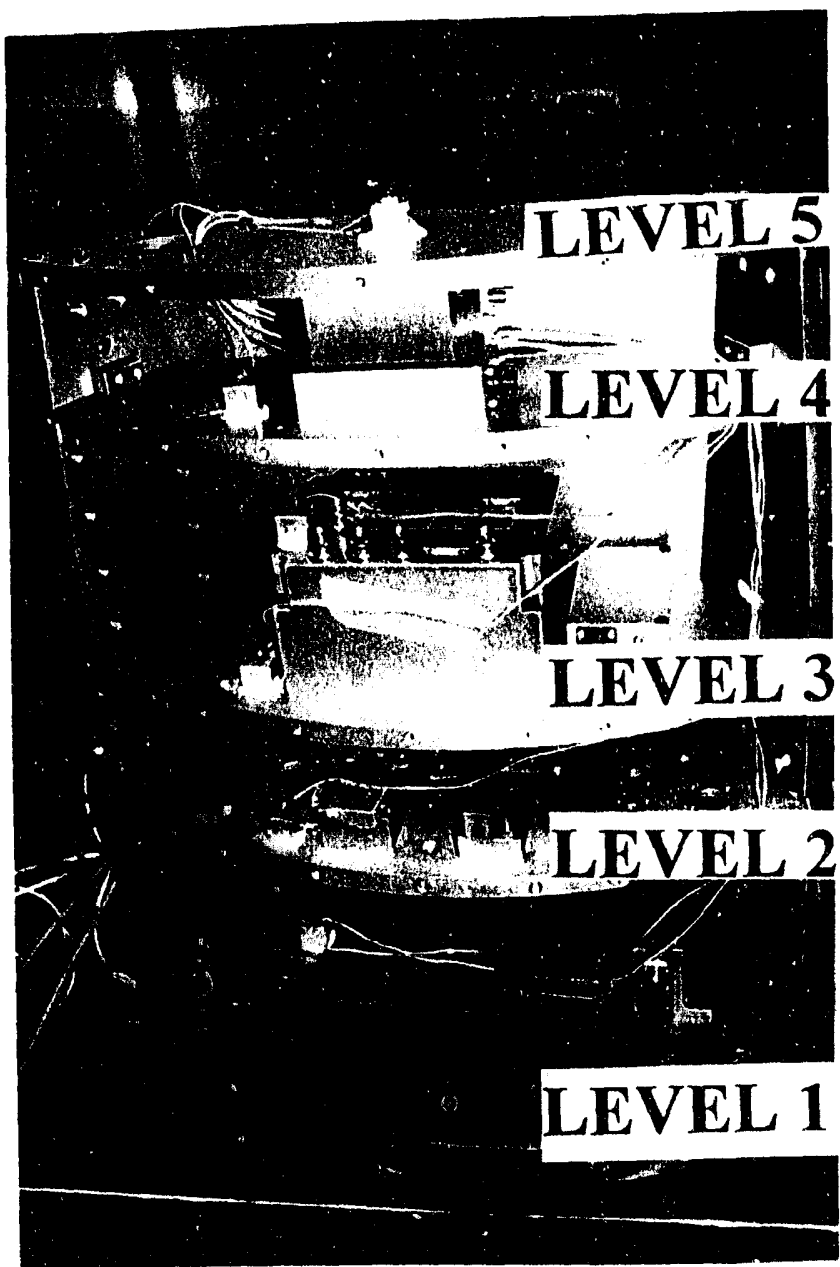

Figure 11: Accelerometer Measurement Locations in the Electronics Rack.

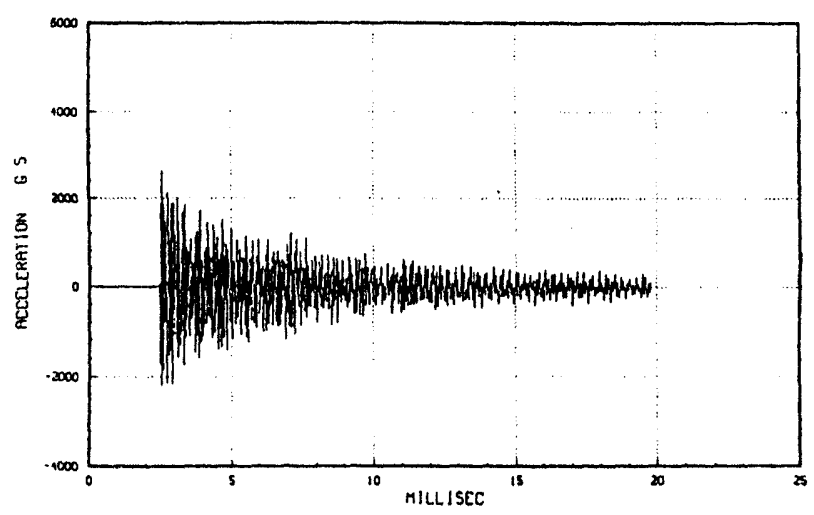

Figure 12: Typical Resonant Fixture Acceleration Response Time History. 


\section{Conclusions}

A novel resonant fixture with an unusually high resonant frequency has been designed and constructed. This small resonant fixture was designed to bolt directly to a larger structure, a simulated payload plate. In this configuration, the resonant fixture does not drive the entire structure, but provides a simulation of the pyroshock source at a particular location on the large structure. This approach allowed the testing of many components with one test configuration. If the usual pyroshock configuration was used, it would be necessary to design and construct many different resonant fixtures (probably one for each component). The resonant fixture meets the shock spectrum requirements to simulate a Vband pyroshock. The resonant fixture was used with simulated flight hardware to simulate the actual pyroshock transmission path and to evaluate the shock mitigating properties of five candidate materials. Rigidamp was chosen as the shock mitigating material because it adequately attenuated the pyroshock transmitted to the components and was easily incorporated into the existing payload hardware.

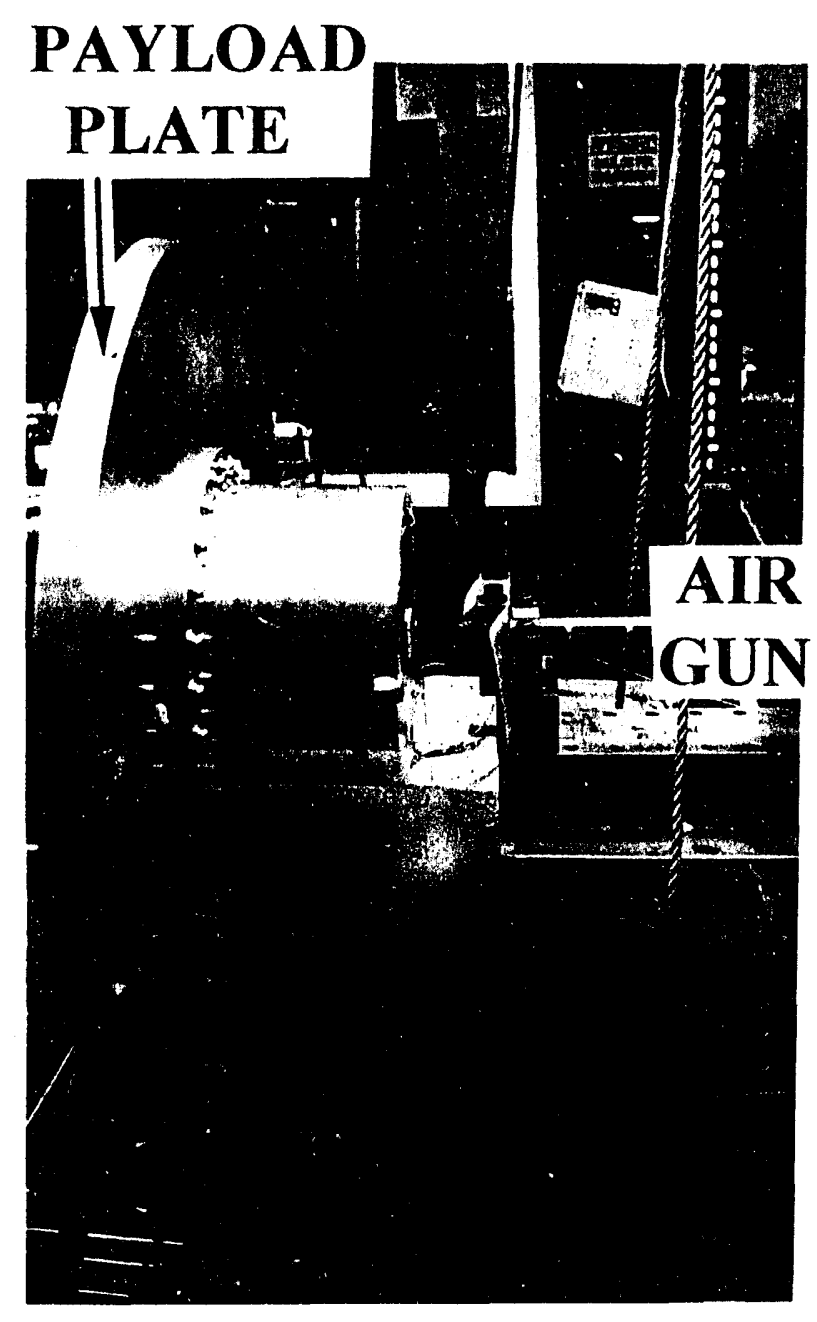

Figure 14: Final Configuration of the V.Band Pyroshock Simulation.

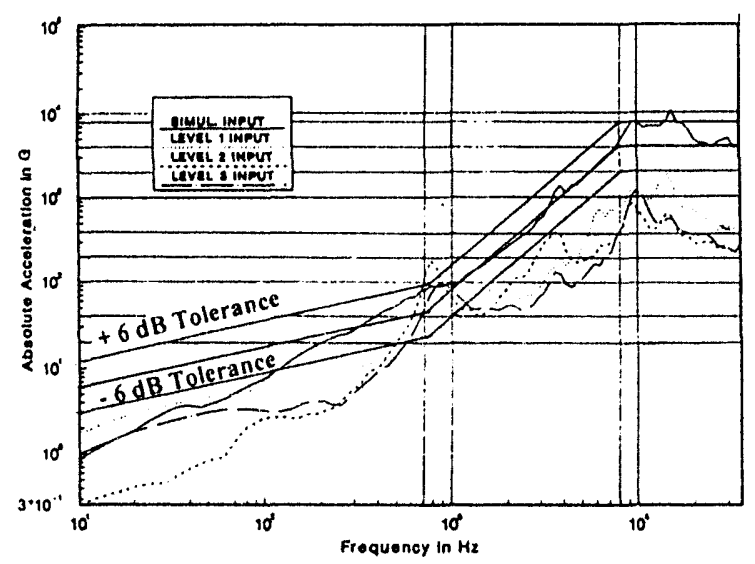

Figure 15: Shock Spectra for Three Measurement Locations Inside the Electronics Rack. 
TABLE 1: COMPARISON OF PEAK VALUES AT FOUR LOCATIONS FOR VARIOUS SHOCK MITIGATING MATERIALS. ${ }^{*}$

\begin{tabular}{|c|c|c|c|c|}
\hline $\begin{array}{c}\text { Shock Mitigating } \\
\text { Material }\end{array}$ & $\begin{array}{c}\text { Resonant } \\
\text { Fixture }\end{array}$ & Level 1 & Level 3 & Level 5 \\
\hline No material & \pm 2000 & & & \pm 180 \\
\hline Ren Shape 450 & \pm 2000 & \pm 250 & \pm 60 & \pm 120 \\
\hline Balsa Wood & \pm 1600 & \pm 100 & \pm 50 & \pm 70 \\
\hline Rigidamp & \pm 1700 & \pm 140 & \pm 40 & \pm 50 \\
\hline Gore-Tex & \pm 2000 & \pm 200 & \pm 90 & \pm 90 \\
\hline $\begin{array}{c}\text { Rigidamp } \\
\text { (Two Layers) }\end{array}$ & \pm 1800 & \pm 150 & \pm 60 & \pm 70 \\
\hline
\end{tabular}

* All values are acceleration with the units of $g$.

\section{References}

1. Bateman, V. I., R. G. Bell, and N. T. Davie, "Evaluation of Shock Isolation Techniques for a Piezoresistive Accelerometer," Proceedings of the 60th Shock and Vibration Symposium, David Taylor Research Center, Portsmouth, VA, November 1989, pp. 273-292.

2. Bateman, V. I., R. G. Bell, F. A. Brown, N. T. Davie, and M. A. Nusser, "Evaluation of Uniaxial and Triaxial Shock Isolation Techniques for a Piezoresistive Accelerometer," Proceedings of the 61st Shock and Vibration Symposium, Vol. IV, October 1990, pp. 161-170.

3. Uncl. memo, from R. M. Zimmerman, 7541, to R. E. Diessing, 9141, subject: Report on Results of T01 Ejector Testing (R360068), dtd. 3/30/90.

4. Harris, C. M., and C. E. Crede, Shock and Vibration Handbook, McGraw-Hill Book Company, 1961, pp. 1-14 to 1-15.

5. Davie, N. T., and V. I. Bateman, "Pyroshock Simulation for Satellite Components Using a Tunable Resonant Fixture," Proceedings of the 14th Aerospace Testing Seminar, Mainhattan Beach, CA, March 1993.

PROCEEDINGS-Institute of Environmental Sciences

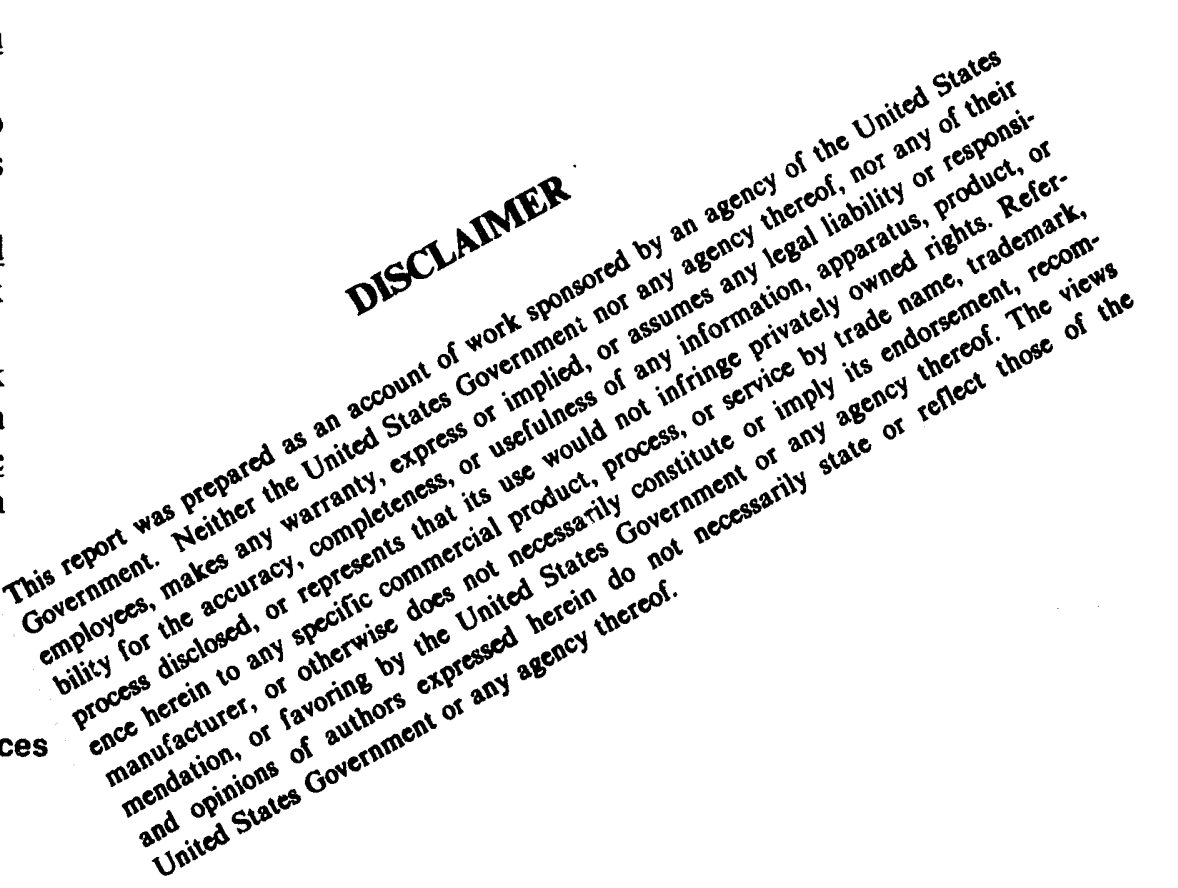




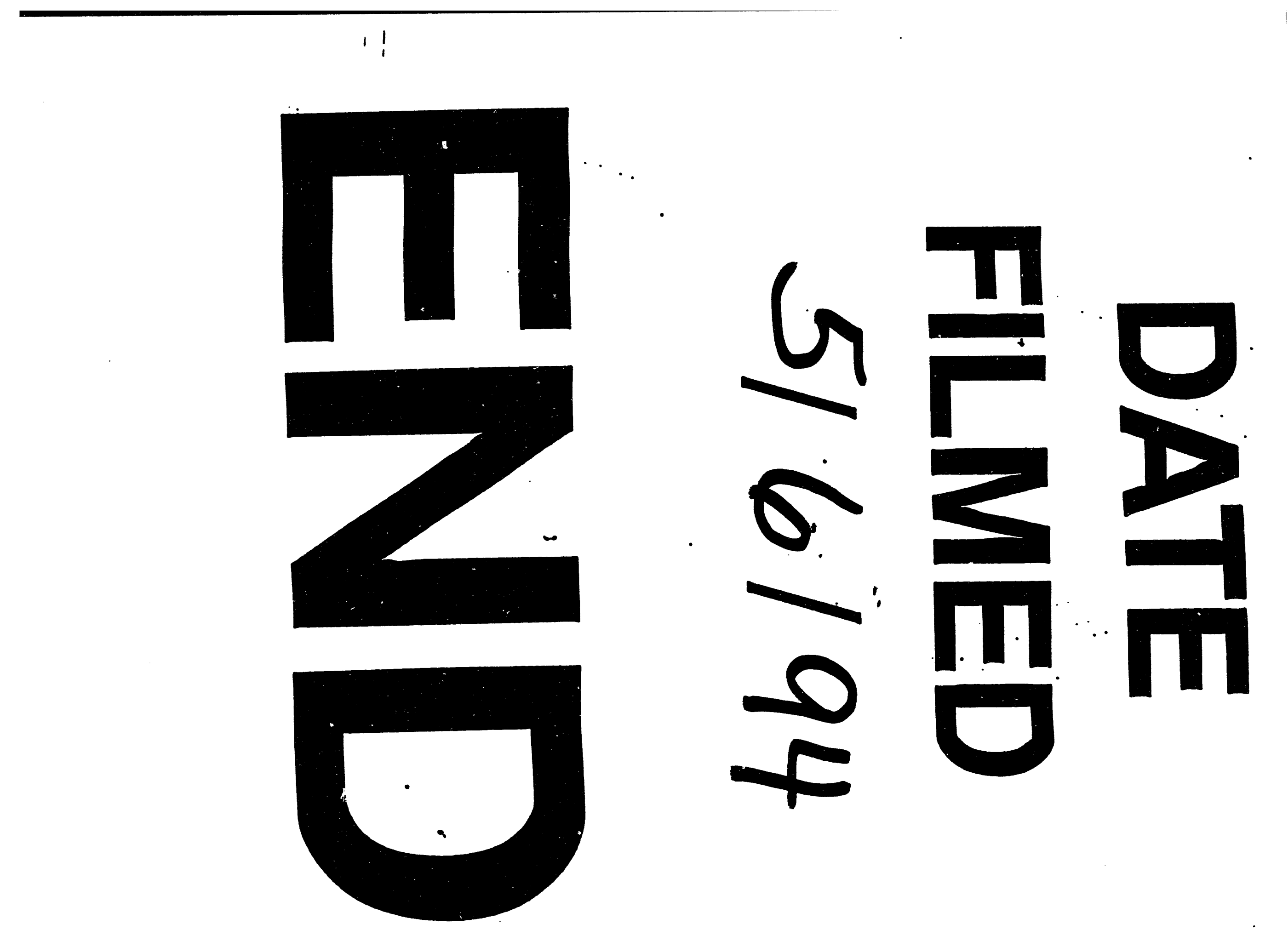


